\title{
One Health approach: A platform for intervention in emerging public health challenges of Kerala state
}

\author{
A. Sukumaran and A. S. Pradeepkumar
}

Integrated Disease Surveillance Project, Public Health Division, Directorate of Health Services, Trivandrum, Kerala, India. Corresponding author: A. Sukumaran, e-mail: 007sukumar@gmail.com, ASP: aspksct@yahoo.com Received: 05-02-2015, Revised: 28-03-2015, Accepted: 10-04-2015, Published online: 01-05-2015

How to cite this article: Sukumaran A, Pradeepkumar AS. One Health approach: A platform for intervention in emerging public health challenges of Kerala state. Int J One Health 2015;1:14-25.

\begin{abstract}
The authors, key functionaries in the Kerala state public health system, review the communicable disease scenario of the state for the past 4 years, and in the background of the One Health concept, opines that the re-emerged discipline is perfectly in tune with the current challenges of the state. The unique model of Kerala state is witnessing newer challenges in its public health arena: The rapidly increasing migrant workforce from relatively poorer states of India, rapid urbanization and its consequent stress on public health, unsolved issues of urban waste disposal, reemergence of many communicable diseases like malaria, more so, the falciparum type, emergence of many zoonotic diseases like Lyme disease, scrub typhus, and Kyasanur forest disease etc. Conventional zoonotic infections such as anthrax and brucellosis remain potential threat for human health as well. Rabies continued to cause major concern from mortality point of view, as well as major drainer of state's budget every year. Leptospirosis has remained major burden among the communicable disease for the past 10 years, and the annual incidence ranged from 2 to 7 per 100,000 population. Having a large section of its people working in various agriculture and animal rearing occupations, the state has all risk factors for propagation of Leptospirosis, but lacks interdisciplinary collaboration in its control and prevention area, the author highlights major avenues for collaboration. Japanese encephalitis appeared as an epidemic in 2011 in two of the southern districts in Kerala, one of the districts being famous tourist spot for both humans, as well as migrant birds. There is ample scope for collaborative research on the source of the virus, and in the subsequent years, the disease had been detected in more districts. Lyme disease was reported for the first time in India, from one of the districts in Kerala, promptly investigated by a joint team from Human Public Health and Veterinary Public Health institutions in 2013, reiterating the role of interdisciplinary collaboration in outbreak investigations. Influenza had been evolving rapidly in the state from the seasonal type earlier, to H1N1 since past few years, now poised for an emergence of MERS Corona and still expected are the more fatal and highly pathogenic types. The migratory bird-pig-domestic birds-human interface being a well-knit network in the state is most suitable for all new variants of influenza virus evolution. Outbreaks of these infectious diseases need investigations by combined teams from departments such as Human Health, Animal Health, and Wild Life. The One Health concept thus becomes appropriate to address such an eventuality. The authors have concluded by identifying the probable avenues for collaborative works in addressing the public health challenges of Kerala state, India.
\end{abstract}

Keywords: Emerging challenges, food borne infections, Kerala's public heatlh, Lyme disease, one health concept, zoonoses.

\section{Introduction}

Kerala state, situated at the South Western corner of India, with geographical coordinates between $8029^{\prime} \mathrm{N}$ and 760 59'E [1] is unique in many ways. It has a highly literate society, with a population of 3.34 crores [2], has a high sex ratio of 1061, birth and death rates are very low compared to other Indian states, Infant Mortality Rate, and Maternal Mortality rates are at par with most advanced countries in the world. These relatively better indices were achieved with a low per capita income, and this model of development was discussed among the global academia as the Kerala Model of development [3] in earlier days. In the public health scenario, diseases usually seen associated with poverty and resource depletion were brought down rapidly and near total universal primary vaccination of infants reduced both infant mortality as well as vaccine-preventable diseases. But as the years

Copyright: The authors. This article is an open access article licensed under the terms of the Creative Commons Attributin License (http:// creative commons.org/licenses/by/2.0) which permits unrestricted use, distribution and reproduction in any medium, provided the work is properly cited. passed, a new Kerala model is being witnessed in the public health sector: Where the state has both communicable as well as noncommunicable diseases rising, newer infections are emerging, older diseases which were eliminated or controlled, re-emerging in some places, and the cost of health care escalating beyond the reach of ordinary man. To supplement this epidemiologic transition [4], novel risk factors are also surfacing in the state such as:

- Influx of large number of migrant laborers [5] from backward states of India, where many diseases like Malaria, Kala Azar, Cholera, etc., are endemic.

- Rapid urbanization of rural villages into modern cities with congested dwelling places, shortage of safe drinking water, poor sewage disposal system, compromised waste disposal facilities-ideal situation for a disease such as Leptospirosis and typhoid.

- Organized resistance of peri-urban or rural populace against urban waste dumping into their backyards further aggravating the urban waste disposals [6]. 
- Uncontrolled encroachment into forest land, deforestation of even notified areas, commercial exploitation of agricultural lands, wherein mono genus cash crops such as rubber, pineapple, and aqua farming replaces the traditional farming practices, these farms indirectly resulting in fertile grounds for profuse breeding of disease carrying vectors like mosquitoes [7].

- And constantly mobile population, in relation to various socioeconomic activities like higher education, trade, and businesses, tourism and pilgrimage-factors favoring water-borne, vector-borne, and food borne infections [8].

- Changing dietary habits, bourgeoning vehicular traffic, substance abuse coupled with a highly stressful lifestyle [9].

Many of the communicable and non-communicable diseases currently having a high prevalence in the state can be traced to some of the risk factors mentioned above. The sociopolitical environment of the 50s and 60s has been replaced, and the developmental agenda redrawn. Consequently, Vector-borne diseases like Dengue, Malaria, Japanese encephalitis, Kala Azar, waterborne infections like Typhoid, Hepatitis A and $\mathrm{E}$, Foodborne infections like ADD, food poisonings, Bloodborne infections such as Hepatitis B and $\mathrm{C}$, emerging infections from the forests, such as Lyme disease, Kyasanur forest disease (KFD), Zoonotic diseases like Leptospirosis, Rabies, Brucellosis, Anthrax and airborne conditions like Asthma, Acute Respiratory Illness, etc., are creeping into the list of illnesses in the disease surveillance database [10]. These are some examples from the human health aspect, and when one looks into the animal health, or wildlife component or the avian fauna part, the situation is likely to be similar and deeper exploration will reveal that many of the risk factors have cross-cutting linkages amply justifying the concept that a healthy community might require a One Health approach synthesizing all the current disciplines and technology.

This paper will examine few of the recently reported surveillance data from the state's Integrated disease surveillance project (IDSP) to identify the multidisciplinary dimensions of the following zoonotic infections and to reinvent a mutually beneficial approach to effectively counter the new threats in the public health arena of Kerala state.

\section{Leptospirosis}

Leptospirosis is one of the most common and seasonal infectious diseases in Kerala and is expanding in its geographical distribution. In recent years, the disease has attained an epidemic status from few sporadic reports in the early 80s. Most of the districts in Kerala have all the favorable climatic and environmental factors for spread of the infection - the high density of population, moist soil, frequent flooding, stagnant pools of water mixed with human wastes and animal excreta, predominantly agriculture occupation, cattle rearing, proliferating rodent population in urban markets and rural fields and added to this, the recent trends in urban cities, dumping urban waste materials into the rural backyards creating environment for further rodent proliferation. There are multiple animal reservoirs for the causative organism and the major vectors for transmission to humans, is also abundant in the environment of the state [11]. The earliest documented data showed a case fatality rate of 5.32 [12] in one of the districts in Kerala, which has gone up 16.9 in 2007, declining to 4.8 in 2013. The annual incidence has shown to be 5.7 per 100,000 population in 2006 increasing to 11.8 (aggregate) in 2011. The Table-1 summarizes the disease burden due to Leptospirosis in Kerala for the past 9 years [13] (Figure-1).

The disease has become endemic in many districts, and there is a well-defined seasonal pattern also, usually with two peaks, coinciding with the rainy seasons of the state.(14). During 2011, there was an epidemic like situation, and the subsequent years appear to be presenting three peaks (Figure-2).

\section{District wise variations}

Kerala state has 14 districts, arranged as an almost longitudinal strip, and the geoclimatic features differ to a minimal extend only between the three distinct zones: A highly populated coastal zone, a midland area where most of the cities and towns are located and a more greener and forested high ranges (Figure-3). All the 14 districts in Kerala have reported human Leptospirosis cases to varying extent. The variations as are seen in the Figure- 4 could be due to

Table-1: The trend of Human Leptospirosis in Kerala from 2006 to 2014.

\begin{tabular}{|c|c|c|c|c|c|c|c|c|}
\hline Year & $\begin{array}{l}\text { Suspected } \\
\text { case }\end{array}$ & $\begin{array}{c}\text { Suspected } \\
\text { death }\end{array}$ & $\begin{array}{l}\text { Confirmed } \\
\text { case }\end{array}$ & $\begin{array}{c}\text { Confirmed } \\
\text { death }\end{array}$ & $\begin{array}{l}\text { CFR } \\
\text { (s) }\end{array}$ & $\begin{array}{l}\text { CFR } \\
\text { (c) }\end{array}$ & $\begin{array}{c}\text { CFR } \\
(t)\end{array}$ & $\begin{array}{c}\text { Annual } \\
\text { incidence/lakh }\end{array}$ \\
\hline 2006 & $\mathrm{n} / \mathrm{a}$ & $\mathrm{n} / \mathrm{a}$ & 1821 & 104 & - & - & 5.7 & 5.6 \\
\hline 2007 & $\mathrm{n} / \mathrm{a}$ & $\mathrm{n} / \mathrm{a}$ & 1359 & 229 & - & - & 16.9 & 4.1 \\
\hline 2008 & $\mathrm{n} / \mathrm{a}$ & $\mathrm{n} / \mathrm{a}$ & 1305 & 136 & - & - & 10.4 & 4.0 \\
\hline 2009 & $\mathrm{n} / \mathrm{a}$ & $\mathrm{n} / \mathrm{a}$ & 1237 & 107 & - & - & 8.7 & 3.7 \\
\hline 2010 & $\mathrm{n} / \mathrm{a}$ & $\mathrm{n} / \mathrm{a}$ & 1016 & 85 & - & - & 8.4 & 3.1 \\
\hline 2011 & 3023 & 238 & 944 & 70 & 7.9 & 7.4 & 7.8 & $2.8-11.8^{\#}$ \\
\hline 2012 & 2709 & 130 & 736 & 18 & 4.7 & 2.5 & 4.2 & $2.2-10.3^{\#}$ \\
\hline 2013 & 2670 & 134 & 814 & 34 & 5.0 & 4.2 & 4.8 & $2.4-10.3^{\#}$ \\
\hline $2014 *$ & 1817 & 96 & 717 & 19 & 5.3 & 2.6 & 4.5 & $2.1-7.5^{\#}$ \\
\hline
\end{tabular}

*Data up to 30-9-14, \#Higher value is when both suspected and confirmed cases are taken together. CFR (s): Case Fatality rate in suspect cases, CFR (c): Case fatality rate in confirmed cases, CFR (t): Case fatality rate among total cases 
environmental peculiarities including rainfall, availability of laboratory facilities for confirmation and also due to gaps in surveillance. However, Trivandrum district, the capital of the state is showing maximum number of cases, consistently over the past 3 years.

There are some major challenges for the state regarding Leptospirosis infection such as;

a. Rapid changes in Clinical spectrum of the disease.

b. Gaps in laboratory surveillance.

c. Lack of coordination in prevention and control measures as well as related researches.

\section{Changes in clinical spectrum of the disease}

In the earlier days, the predominant symptoms were due to hepatorenal damage resulting in a syndrome termed Weils disease, and the causative organism were believed to be Leptospira icterohaemorrgiae. But over the years, the clinical spectrum has shown range of organ involvement, and recently the syndrome of multiorgan dysfunction syndrome as well as acute respiratory distress syndrome has become the immediate cause of death in many patients [15]. There is no convincing explanation for these changes, but could be due to the changes in the prevalence of local serovars or changes in virulence of the organism or both. These are areas for more collaborative researches and diagnostic endeavors.

\section{Gaps in laboratory surveillance}

The bar diagram also hints at gaps in reporting of this major public health problem among the districts. Prior to 2011, the state was accounting all probable cases without stressing on laboratory confirmation. But, when an apparent epidemic occurred

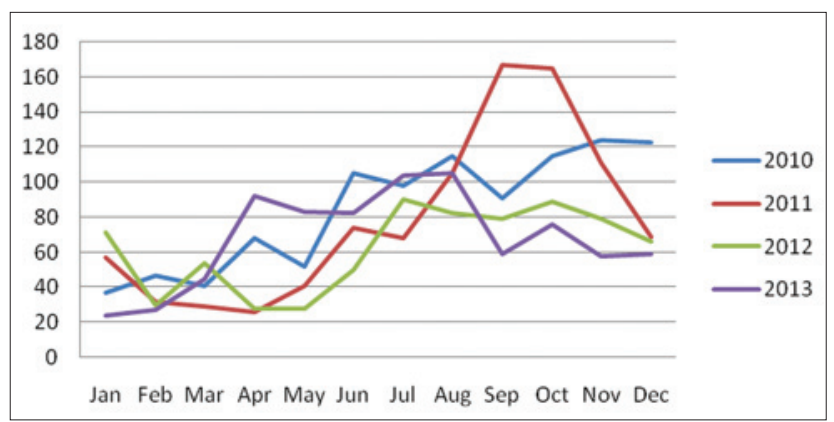

Figure-1: Seasonality of Leptospirosis in Kerala for 2010-2013.

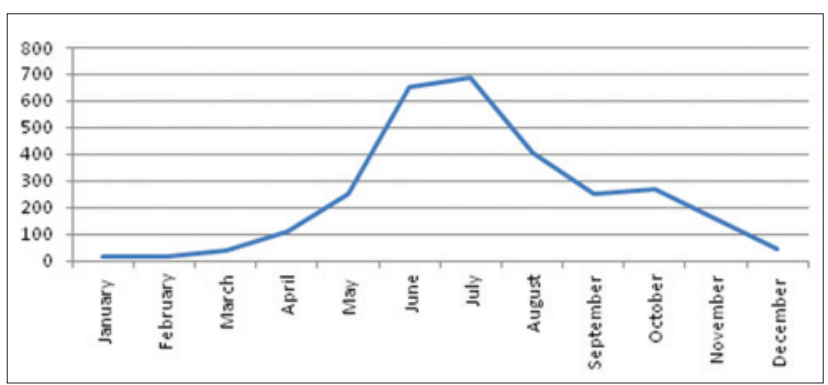

Figure-2: Rain fall pattern in Kerala state-2011 (Source:http//.www.prokerala/climate/html. Retrieved on 16.5.13.) [14]. in the following years, there was a rethinking on the diagnostic criterion, and presumably due to a political pressure also, the system resorted to segregate the data based on laboratory tests done. Figure- 4 showing only the ELISA confirmed Leptospirosis cases, and the facility for this test is available in major cities only. Rapid tests are not available in many rural institutions, and hence the actual disease burden could be much higher. Many districts may have large number of suspected cases than the confirmed. None of the medical colleges, either government or private, is equipped to do the molecular or genetic studies on Leptospira. Facility for doing the microscopic agglutination test

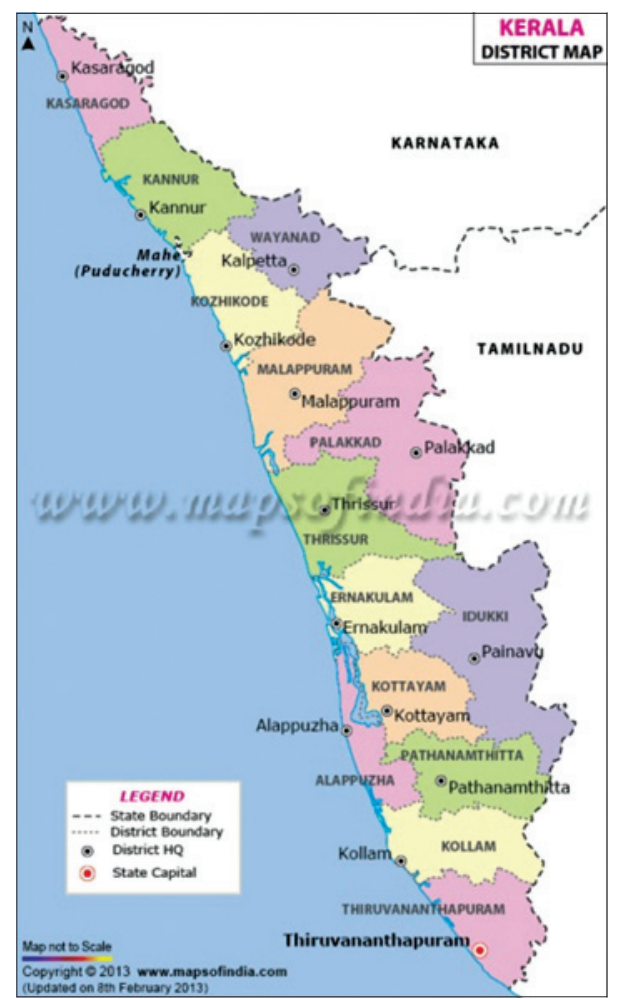

Figure-3: Map of Kerala state showing the layout of its districts.

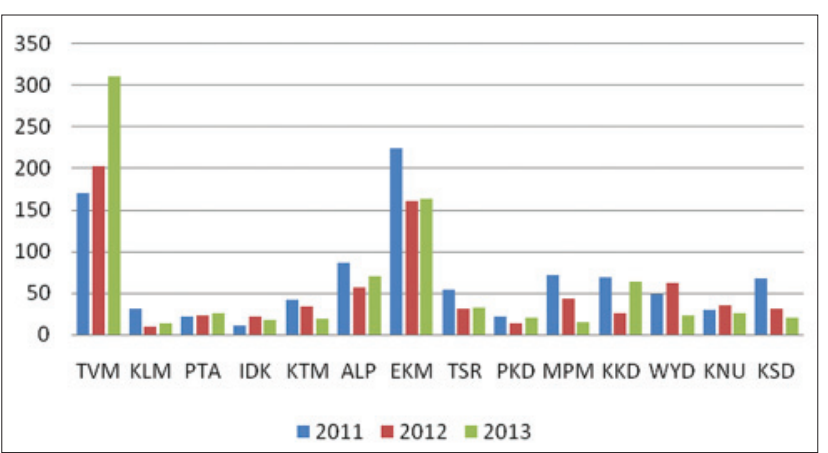

Figure-4: District-wise comparison of ELISA confirmed Human Leptospirosis in Kerala state 2011-2013. The three letter codes represent the names of districts: from Trivandrum in South to Kasargode in North (TVM: Trivandrum, KLM: Kollam, PTA: Pathanamthitta, IDK: Idukky, KTM: Kottayam, ALP: Alappuzha, EKM: Ernakulam, TSR: Thrissur, PKD: Palakkad, MPM: Malappuram, KKD: Kozhikode, WYD: Wayanad, KNU: Kannur, KSD: Kasargode). 
(MAT) test, considered to be the gold standard in laboratory confirmation of Leptospirosis [16], is available only at the Veterinary University Center at Mannuthy, Thrissur, where there are many bottlenecks for testing human samples on a routine basis. There was one private institution doing MAT earlier in one of the mid Kerala districts [17], but the trained microbiologist in that center-left the institution few years back, and since then there is a vacuum there also. Consequently, serovar prevalence among human Leptospirosis is largely unknown in Kerala.

\section{Research on Serovar variatons}

There are hardly any serovar studies in human Leptospirosis in Kerala, at least in the database of the directorate of health services. But Veterinary College, Mannuthy, Thrissur, Kerala, a leading research center in animal Leptospirosis has undertaken serovar studies with assistance from Regional Medical Research Center, Port Blair, Andamans [18]. Their study done with MAT revealed that 8 different serovars are predominant in 145/205 canine sera collected from three different regions of the state. These were L. autumnalis, australis, canicola, icterohaemorragia, pomana, etc. Anecodtal evidence from KVASU Pookode mentions about the prevalence of L. hadjo in cattles. Serotyping from human samples at RMRC Port Balir had shown autumnalis, australis, andamanica, bratislava, pomana, hadjo, icterohemorrhagia, and grippotyphosa as high prevalent types [19]. Collaboration with the Veterinary University would be an ideal option for studies to identify the serovar prevalence in human Leptospirosis thus for long-term planning for Leptospirosis control in the state.

\section{IEC/BCC campaigns}

In Kerala state, the term Leptospirosis has been almost completely replaced by the layman's terminology, rat fever (Elippani, a local slang for fever spread by rats; Eli=rat and Pani=fever), and all preventive measures are targeting rodent eradication. Decentralized Peoples plan campaigns by the local self-governments have given high priority for the rodent control using rat poison and as periodic campaigns. However, the results of these community-based campaigns appear to be not very encouraging. The role of infected urine of domestic animals such as dogs, cattle, and pigs in the spread of human Leptospirosis needs to be highlighted in the community so as to make the preventive measures more effective. High-risk occupations like working or recreations in contaminated surroundings have already claimed many lives, and the role of disinfecting before and after such occupations needs to be stressed in the control aspects.

Under this context, the recently launched One Health initiative at Kerala Veterinary and Animal Sciences University (KVASU-Pookode, Kerala - Center for One Health Education, Advocacy, Research and Training [COHEART] Project) becomes a good opportunity for Leptospirosis control in Kerala state in following ways:

a. Establish a MAT diagnostic center, under COHEART, for study of human Leptospirosis

b. Establish linkages with directorate of health services for testing of human samples

c. Research for mapping of seroprevalence of various serovars in both human and animal Leptospirosis

d. Education campaign for farmers on proper disinfection of cattle sheds, dog houses, and immediate environment

e. Evaluate the vaccine components in Leptospira vaccine for domestic animals

f. Implement scientifically proven IEC/BCC campaigns for Leptospirosis control.

\section{Japanese Encephalitis}

Japanese encephalitis is an acute inflammatory disease of human brain and its coverings due to an infection with a virus belonging to the group of flavivirus, resulting in varying degree of mortality and morbidity among the affected population. The disease spreads from its natural host, usually cattle egrets, pigs, cattles, ducks or wild birds, through the bite of an infective vector, a mosquito belonging to the genus Culex or Mansonii. These mosquito species breed abundantly in irrigated paddy fields and other water collections. The infection in a human being is accidental and terminal for the virus, i.e., its life cycle ends with a human host, whereas among the bird - mosquito-pig axis it is perpetuated indefinitely. JE viral activity has been widespread in India. The first evidence of the presence of JE virus dates back to 1952. The first case was reported in 1955 and since then outbreaks have been reported from different parts of the country [20]. In Kerala, JE has occurred in many districts, but the Southern districts of Kottayam, Kollam, and Alappuzha appears more prone (Table-2). In the recent years, the disease has been detected in Northern districts of Palakkad, Malappuram, Kozhikode, and Kannur, from areas, typically having plenty of water holdings and paddy fields. Migratory birds from different parts of the globe are also suspected to play an important role in the introduction of JE virus into newer geographical regions [21]. In a recent development, from the laboratory aspect, some of these cases were found to have the differential diagnosis of West Nile Fever, an illness with similar clinical and epidemiological characteristics.

Environmental characteristics of Japanese encephalitis virus:

- Primary hosts of the virus are water birds and animals like pigs.

- Pigs act as virus multiplier and amplification vessel and usually do not show much symptoms [22].

- Transmission is through the mosquitoes of Culex and Mansoni sp., which breed abundantly in ecosystems like paddy fields and other water holding areas.

- Migratory birds of various types might be carriers 
of the virus over long distances and different geographical regions.

- Climatic variations and farming practices may be influencing the vector bionomics.

- Salinity of the water might be a factor preventing mosquito proliferation since most of the migratory birds are seen near fresh water collections.

The following satellite image captured during a recent report of a JE in Kolachery area of Kannur district, depicts all the environmental factors favoring a $\mathrm{JE}$ virus transmission: Presence of a bird sanctuary (Mundery bird sanctuary) where lot of fresh water birds, both native and migrant, large areas of paddy cultivation fields, a check dam to prevent salt water entry into the paddy fields (Kattampally barge) and location of the JE case, in Perumachery. The local community mentions about plenty of wild pigs in and around the hillocks and shrubs on the North Eastern side of the paddy fields. Teams which did the field epidemiological investigation detected plenty of Culex mosquitoes from cattle sheds and larvae from the paddy fields in the area.

Google satellite map showing the location of the recently reported JE in Kannur district of Kerala- also reveals the interrelation of a check dam to prevent salt water entry to paddy fields, and the consequence of flocking migratory birds which might be one of the factors for introduction of the virus in the area (Figure-5 and Figure-6).

The Central Surveillance Team from New Delhi during the investigation of the JE outbreak in South Kerala during 2012 also reported the occurrence of cases mainly in the water logged areas of Alappuzha and Kollam districts where a similar environment

Table-2: Data on JE cases reported in Kerala since 1995.

\begin{tabular}{lccl}
\hline Year & Cases & Deaths & Districts affected \\
\hline 1995 & 0 & 0 & - \\
1996 & 106 & 32 & PTA, ALP, KTM, EKM, PKD \\
1997 & 61 & 7 & KLM, PTA, ALP, KTM, EKM \\
1998 & 99 & 14 & ALP, KTM, IDK, EKM, PKD, MPM \\
1999 & 46 & 4 & PTA, ALP, KTM, TSR, PKD, MPM \\
2000 & 11 & 1 & KLM, KTM, EDK \\
2001 & 2 & 0 & EKM \\
2002 & 1 & 0 & MPM \\
2003 & 14 & 0 & PTA, KSD \\
2004 & 11 & 0 & TVM, PKD, KNU \\
2005 & 0 & 0 & - \\
$2006 *$ & 13 & 1 & ALP \\
2007 & 0 & 0 & - \\
2008 & 0 & 0 & - \\
2009 & 0 & 0 & - \\
2010 & 0 & 0 & - \\
2011 & 37 & 2 & ALP, KLM, KKD \\
2012 & 3 & 1 & KTM, TSR \\
2013 & 2 & 0 & PKD, KNR \\
Cum. total & 406 & 62 & All districts except WYD \\
\hline
\end{tabular}

Source: Statistical dept. DHS Kerala. TVM: Trivandrum, KLM: Kollam, PTA: Pathanamthitta, IDK: Idukky,

KTM: Kottayam, ALP: Alappuzha, EKM: Ernakulam,

TSR: Thrissur, PKD: Palakkad, MPM: Malappuram,

KKD: Kozhikode, WYD: Wayanad, KNU: Kannur,

KSD: Kasargode prevailed. They also suggested to undertake a sero surveillance of serum samples from herons, ducks, and cattles with support from Animal Husbandary officers. Facilities for laboratory testing of JEV are available with the NIV unit at Alappuzha, Rajeev Gandhi Center for Biotechnology, Trivandrum and also at MCVR Manipal. West Nile Fever, a clinically similar condition emerging as a major public health issue in Western hemisphere [23], is also suspected in some of these cases, but there is limited laboratory facility for differentiation. We need to develop centers for differentiating JEV from WNF virus in the long run.

Japanese encephalitis is an area, for effective collaboration between Veterinary Public Health and Human health experts. The scope of collaboration can be

- Serosurveillance studies on the animal/avian hosts in a given area.

- Mapping of high-risk zones based on the combination of ecological factors.

- Sensitization of planners and policy makers, regarding the conflicts in the outcome of developmental projects like check dams.

\section{Rabies}

Rabies is another zoonotic infection, and a dreaded disease affecting the human brain, usually following an infected animal bite, and almost always fatal. There is an estimated 50,000-60,000 deaths due to human rabies every year, globally and all the continents except

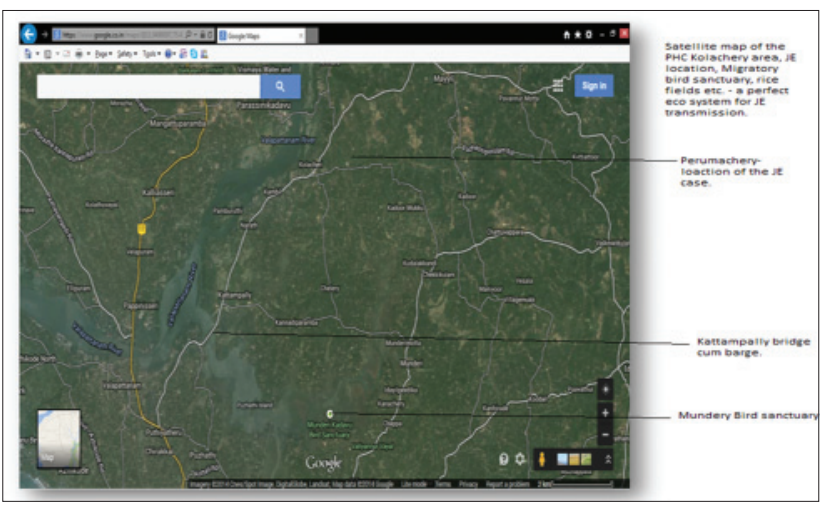

Figure-5: Satellite image of the ecosystem at the area of recent JE case in Kannur district.

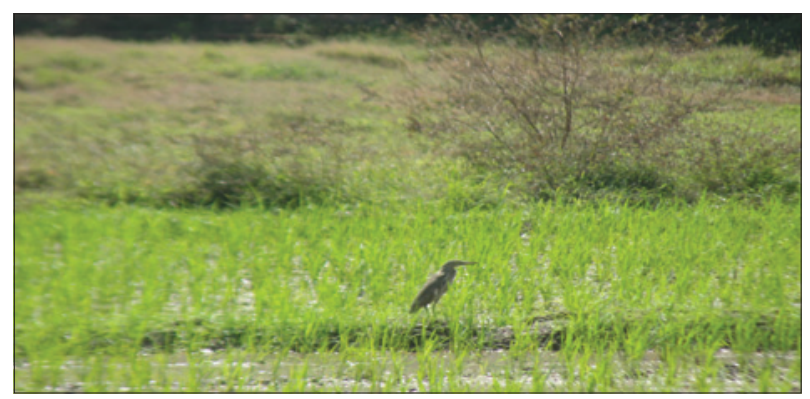

Figure-6: Ecological factors suitable for Japanese encephalitis-paddy fields, water bird, and culex vectors. Scene from Kannur district 2013. 
Antartica are affected with this disease [24]. The disease is caused by a virus of Rhabdoviridae sp. entering into human body through bites or licks of an infected animal, usually a dog, but occasionally can also result from cats or bats or other animal bites. The tragedy of this disease is that, there is a long incubation period of about 3 months, even pet animals can get the infection and transmit it, diagnosis is possible only when the classical symptom of hydrophobia appears, and the patient is conscious till his last breath. Our dogs are mostly let off to wander in the streets most often, not vaccinated routinely, and nowadays, people have started keeping the pet dogs inside their houses itself thereby chances of exposure is more even for children and elderly. The number of dog bites and the amount spent on anti-rabies vaccination for humans are showing staggering figures. Even though Kerala has introduced the Intra Dermal Rabies Vaccination [25] so as to reduce the cost of care, the annual budget still falls short of the actual requirement each year. The data on dog bites and rabies in Kerala for the past few years are mentioned in Table 3) (Source: IDSP SSU Kerala). The data are alarming, and the demand for vaccination will be many folds due to the fear and apprehensions of the people around a reported rabies case. Besides, there will be a good number of bites or licks by other animals also, resulting in huge financial burden for the state, on account of the vaccine. All deaths are presumably due to inadequate vaccination of humans (post exposure vaccination).

Rabies is completely preventable by periodic vaccination of all dogs and post exposure vaccination of humans. Since there are reports of rabid dogs biting domestic animals like cows, cats, monkeys etc., a rabies case in an area usually is followed by many controversies. Need for vaccinating all members of the case's family, all persons receiving milk from a cow bitten by a suspect dog, all persons who had consumed meat from a cattle suspected to have died due to some illness, whether to vaccinate persons bitten or licked by a vaccinated dog, etc. are some of such issues faced by public health officers of the area. Eliminating stray dogs has remained unattainable due to various kinds of restrictions, animal birth control has been undertaken only in very few areas, and mandatory vaccination and certification of pets has not percolated into the community to the desired levels.

One Health/COHEART can take up the challenge of making our state Rabies free on a phased manner. Plan of action could be:

- Collaborative efforts for Rabies Free Kerala by 2025. Animal Husbandry Department, Directorate

Table-3: Details of dog bites and Human Rabies in Kerala.

\begin{tabular}{lcccc}
\hline Year & 2011 & 2012 & 2013 & $2014 *$ \\
Dog bites & 6323 & 25204 & 34154 & 58537 \\
Rabies cases & 10 & 13 & 11 & 10 \\
Rabies deaths & 10 & 13 & 11 & 10 \\
\hline
\end{tabular}

*Provisional of Health Services (Human) and Animal welfare board to be major collaborators.

- Mobile Canine Sterilization Vans to be set up on a regional basis, with trained officers and support staff.

- Sensitize the Local Self Governments (LSGs) (LSGs denote the decentralized administrative units in the state, also called as Local Self Governments) - Panchayaths, municipalities and corporations for resource allocation for the camps.

- Additional resources can be tried through external agencies.

- Sterilize, vaccinate, and certify all pet and stray dogs. To be monitored with appropriate surveys and documentation.

- Conduct periodic community level awareness programs on Rabies control. Celebrate World Rabies day on every September 28-Death Anniversary day of Louis Pasteur, the great scientist who developed the first rabies vaccine.

\section{Brucellosis}

Brucellosis is a re-emerging zoonotic disease effecting about 500,000 cases per year globally [26], the Mediterranean and Arabian Peninsula countries being the most affected. The disease is caused by a coccobacilli intracellular bacterium having 4 distinct species, Brucella melitensis in goats and sheeps, Brucella abortus in cattles, Brucella suis in pigs, and Brucella canis in dogs, all can cause infection in man with varying severity and organ involvement. Musculoskeletal and reproductive organs are predominantly affected resulting in chronic diseases of bone and joints or reproductive failures. In animals, the disease causes repeated abortions, retained placentae and joint infections. Humans are infected by consumption of unpasteurized milk or partially cooked meat of infected animals and Brucellosis is an occupational hazard for people engaged in diary and meat industry. The annual incidence is estimated to be about $1.2-70$ cases per 100,000 population per year and is a major cause of pyrexia of unknown origin in low-income countries [27]. Brucella is also one of the oldest biological weapons developed by various countries involved [28].

In Kerala, Brucellosis is not reported in the routine surveillance system, but case reports are not uncommon in both human and animal health sectors. Some of the polyarthritis cases attending the outpatient departments of hospitals could be due to Brucella infection. Recently, a confirmed case was reported from Malappuram district, in a person who had returned from Oman (a Gulf country, where he was working in a slaughter house) [29]. Considering the large number of non-resident Keralites working in the middle east countries, more and more people engaged in cattle rearing, diaries, milk industry, meat industry, pigs, and goat farms, and thousands of workers in these industries in our own state, where the 
safety profile is usually not to the desired levels, it is worthwhile to set up a surveillance system for the Human Brucellosis in Kerala. Seroprevalence studies by researchers of the Veterinary colleges have shown much higher incidences: $2.45 \%$ in general population, $1.14 \%$ among veterinarians [30], 1.47\% among humans (Vinod, et al. 2005).

COHEART can set up a regular surveillance system for Brucellosis, initiate educational programs for occupational safety in these sectors and formulate policy guidelines for safety of various materials used in these industries.

\section{Anthrax}

Anthrax is a bacterial infection affecting both humans and livestock to varying extend, throughout our country. Of the three different forms, the pulmonary, gastrointestinal and cutaneous forms, the latter is the least severe while the other two forms are usually fatal. The bacteria survives in the soil and environment for many years, in its sporulated form, and after ingestion or inhalation, it multiplies inside the body of the host and causes the various symptoms, which if untreated, results in death. Even after the death of the animal, the extruding blood and body fluids contains abundant bacteria, which immediately sporulates and the spores are released into the environment [31]. The bacteria/spores are also seen in the skin, hide, horns, meat, and milk of the infected animal, and unsafe handling of these materials are of high risk for transmission to the persons engaged in related industries. Like Brucella, anthrax bacilli are also potential bioterrorist weapon [32].

As per National Animal Disease Referral Expert System data, anthrax features as one of the top ten animal diseases reported in India and also as one of the major causes of death in livestock. Anthrax has been reported in eighteen states including Kerala during the last two decades (1991-2010). (Dr. H. Rahman, Dr. Gajendragad and Dr. S. Uma. ICAR, Hebbal, Bengaluru, India 2012) [33].

The incidence of human anthrax in Kerala is largely unknown. Cross-border transportation of cattle for slaughter industries, some of which were allegedly sick, used to create a scare in some of the bordering districts frequently. This is a potentially serious situation, where the One Health platform can intervene for appropriate action. The plan of action could include:

- Sensitization of the service providers, both human and veterinary professionals for disease surveillance, reporting, precautions during handling, and also promote vaccination programs.

- Educating the workers engaged in the cattle and meat industry for personal protection against the infection.

- Advocacy among the policy makers for ensuring the occupational safety of the workers in industries handling the hide, horns, meat, and also diary sectors.
- Promoting vaccination against Anthrax for the vulnerable category.

\section{Lyme Disease}

Lyme disease, a spirochete caused zoonotic infection have been a major illness in the western hemisphere, especially United States [34], but not reported in India till recently. In February 2013, a cluster of acute febrile illness with rash and myalgia were reported among a group of 6 women engaged in coffee plucking job in a plantation close to the reserve forest area of Chettiyalathoor under PHC Noolpuzha of Wayanad district, Kerala state [35]. Not responding to the usual treatment in the local hospitals, these women were subsequently referred for tertiary care centers, where, on investigation, the blood samples became positive for Lyme borelliosis infection and negative for other common infections in the area, such as Malaria, Scrub typhus, Leptospirosis, and Dengue. The tests were done at an authentic ICMR reference laboratory, the Manipal Center for Virological Research. The initial field investigation by the surveillance team of District Medical Officer (Health) Wayanad revealed that one of the patients had a swollen tick adherent to her body, and she had the characteristic rash on her groin region.

A detailed outbreak investigation was conducted jointly by teams from Human Public Health (IDSP Kerala) and Veterinary Public Health (KVASU Pookode) along with Microbiologist of MCVR (Manipal Center for Virological Research, Karnataka, India), and few more serum samples were collected from the area and tested (Figures -7 and 8 ) The tests involved ELISA, later confirmed by Western Blot.

The field investigation by the multidisciplinary team, surveyed for more symptomatics, collected the vectors (Ixodes scapularis) and sent for species identification as well as incrimination studies (Figure-9). The local community endorsed the view that the deer population in the area has grown to nuisance levels, many of them routinely encroaching into their peri-domestic plantations and farms, people had been experiencing various levels of dermatitis following the tick bites, and few of the persons who had severe tick bites in the past continuing to experience various physical ailments including polyarthritis like symptoms, all of which are known consequences of Lyme disease.

In the subsequent weeks, a few more cases of fever with rash and poly arthralgia similar to the initial reports were reported from the same area, and serum samples were sent to the MCVR for testing. Out of 8 samples tested 4 became +ve for Lyme and one patient died. Intensive tick control measures were implemented, and the outbreak was controlled. But Wynad district, having large number of tribal people, living in close proximity with forest land, and all of the reserve forests in the region having a large deer population is clearly vulnerable for this infection.

This incident was an eye opener for the public health planners and administrators in the district and 


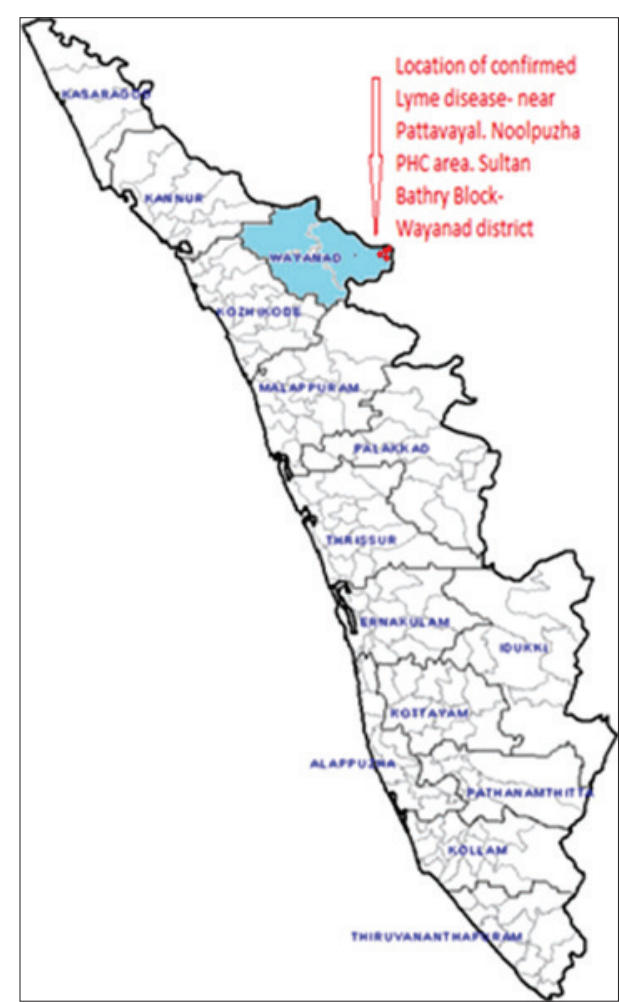

Figure-7: Kerala map showing the location of the Lyme disease - a small village near the Kerala-Karnataka-Tamil Nadu border and forested area.

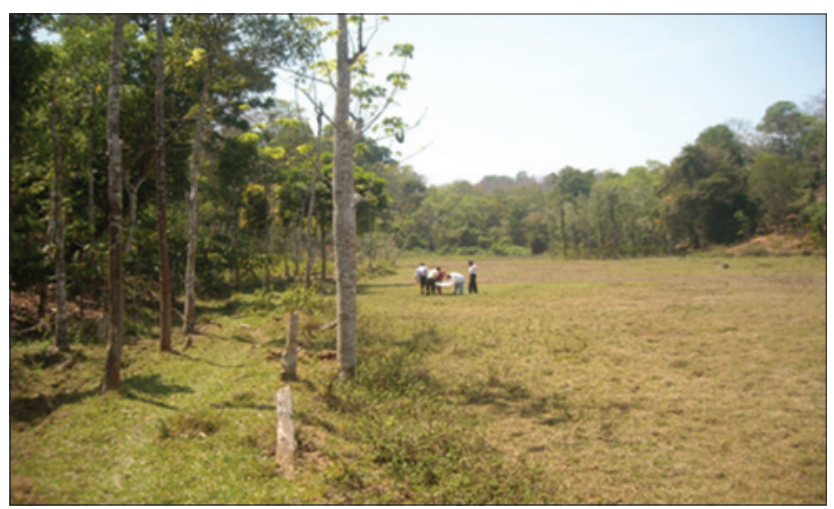

Figure-8: The Lyme disease reported area - a typical ecosystem with forest on one side, human habitation on the other, and the deer grazing fields in close proximity. The teams searching for the ticks in the fields.

also in the state headquarters:

- There is a highly favorable environment in Wayanad district of Kerala for the emergence of newer zoonotic infections like Lyme disease.

- The disease investigation requires experts from many disciplines, like Human Health, Veterinary Public Health, Wild Life experts, Medical Entomologists and Microbiologists.

- Local community in the affected area might have been suffering silently in the past, but the health system was not able to identify or act.

- The disease control needs collaboration of multiple departments like Health, Veterinary, Forest and Wildlife, Tribal and also the district administration.

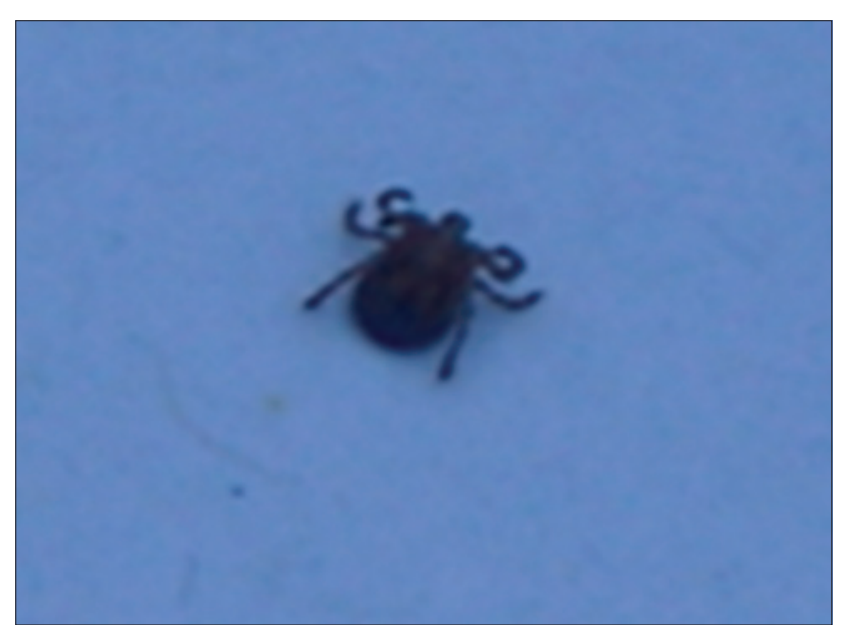

Figure-9: One of the ticks collected from the area- identified as Ixodes sp.

- One Health approach is fully justifiable in similar situation and can be developed as a model for our country.

COHEART can collaborate with the human health department for investigation, laboratory confirmation, and educating vulnerable community in prevention and control measures against diseases similar to Lyme borreliosis, or KFD which will be discussed below. These diseases are, in fact, apt examples where in human, animal and environment factors balance each other for benefit and safety of all.

\section{KFD}

KFD is another reemerging viral hemorrhagic fever, affecting primarily the monkeys and other wild animals, first reported in 1955 from the Kyasanur forests of Shimoga district in Karnataka.[36] (Proceedings of $9^{\text {th }}$ Pacific Science Congress-1957. Authored by Telford. H. Work, Director Indian Council of Medical Research and Harold Trapido Dy. Director, Viral Research Center Pune, Maharashtra, India) Since then, the disease has spread to larger areas surrounding this forest land, and now has reached southern region of the forests in the Western Ghats into Kerala state also. The disease caused by a virus of Flaviviridae group has its natural cycle between the ticks of Haemophysalis spinigerae and the wild animals like monkeys, shrews, rodents, small birds, spilling over to domestic animals like cattles, buffalos, goats etc., which graze in the infested forests, and humans are accidentally infected by the bite of the infected ticks. KFD has a clear seasonal pattern coinciding with the life cycle of the ticks, with epidemic proneness during the pre-monsoon months of January to May. People who reside deep inside the forests, forest personnel, picnickers, and adventure tourists are at high risk of getting infected if protective measures are not used.

In Kerala, three incidents of this disease have been reported in the past 2 years. One confirmed case from the Alathur tribal colony under Noolpuzha PHC area of Wayanad district in April 2013 [37] and the 
second incident occurred among a group of 6 women who were working under the NREG program, and belonged to the same colony, one-year later, in March 2014 (Figure-10).

In both these instances, the laboratory confirmation was done at MCVR Manipal. After a few months, a third incident was reported from the Karulai forest area of Malappuram district [38] where 8 persons belonging to a primitive tribal group (Kattunaikkars) were tested positive for KFD [39], and two persons have reportedly died due to similar symptoms in the same area, few weeks prior, but could not be tested in laboratory. The first two locations are close to the KFD confirmed forest belt of Karnataka, and the third one, though not directly in continuation of the Shimoga belt, is within the dense forest of the Western Ghat in Malappuram district of Kerala, South East to the known KFD hot spot in Karnataka. This probably is an indication, that the disease is slowly spreading south wards (Figure-11).

In another interesting event, in a place called Budhanur in Alappuzha district, in the Southern part of Kerala, during early 2014, a monkey death was detected by the local people, informed to the Vetrinary Department, who sent the sample for analysis at KFD surveillance center at Shimoga, and it was confirmed that the monkey died of KFD [40]. Though there were no human cases or geographical continuity with the earlier mentioned forest areas, the incident is significant from a public health perspective. In many places in Kerala, the population of monkeys is increasing, and they are moving closer to human populations due to the depletion of their forest resources.

On a public health perspective, these incidences are significant due to following:

- The small hot spot of KFD in Shimoga district in 1955 has expanded to a larger area over the past 60 years.

- The disease is affecting the primitive tribal groups, who are otherwise also deprived of many basic needs for a decent living.

- The remoteness of the affected people results in late detection, and prevention.

- Vaccination of the high-risk groups also becomes difficult due to the remote locations.

- Spilling over of the infected monkey population into human habitations can aggravate the situation further. The whole eastern highlands of Kerala being a continuous zone of the Western Ghat, the virus can slowly spread to the whole of this state in a distant future, if early and effective measures to control are not implemented (Incidentally, after this document was prepared, there occurred a huge outbreak of KFD in Wayanad district of Kerala, started on 16-1-15 and still continuing, resulted in 145 probable human cases, 51 confirmed by polymerase chain reaction test, 7 confirmed deaths, $>25$ monkey deaths in various places adjoining the forest range, and the situation is still not under control. I was personally involved in the outbreak investigation, and we could identify dead monkeys in the epicenter of the outbreak, and the ticks collected from the forest floor proved to be haemaphysalis kyasanuriensis.

KFD thus becomes another example of man-animal-environment interface with a delicate balance between well-being of each other, with potential for the explosion on slightest disturbance. One Health Initiative has a great role to play in maintaining this balance. The COHEART Center situated in a strategically advantageous district, can collaborate with the Shimoga center for KFD surveillance among wildlife, domestic animals, tick incrimination and thereby identification of hot spots, and also track the geographical expansion of the virus.

\section{Food Borne Infections}

Food, water, and air, the three basic necessities for sustaining human life are slowly getting

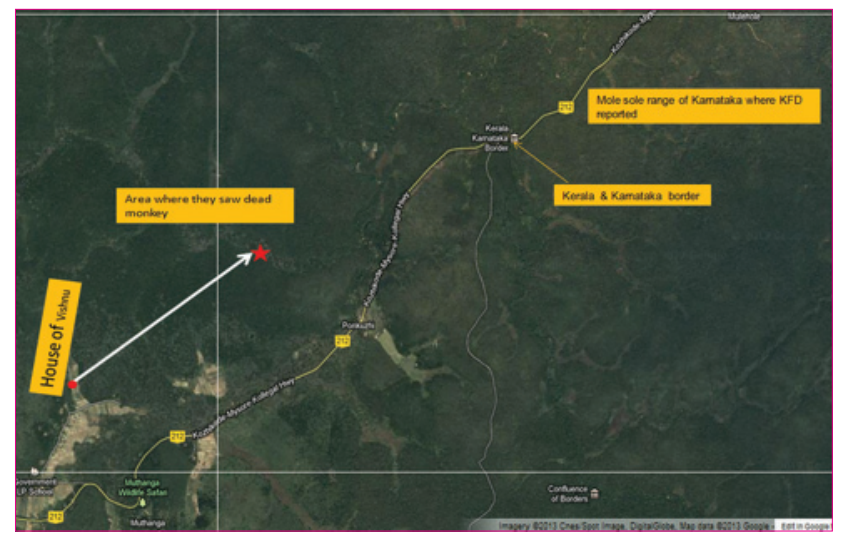

Figure-10: Google map showing the location of recently reported Kyasanur forest disease in Wayanad district of Kerala.

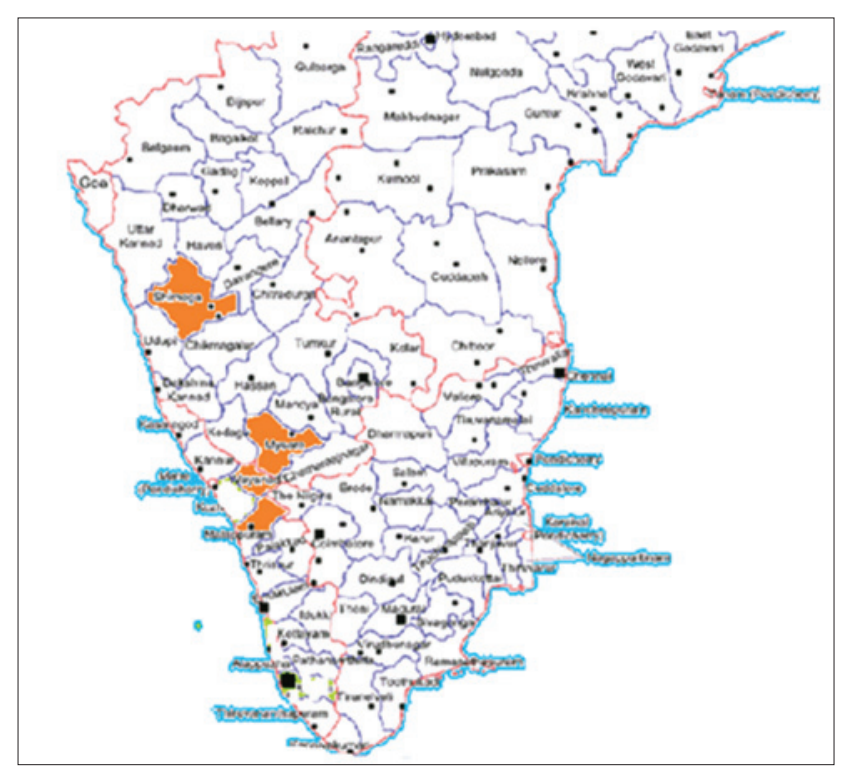

Figure-11: Atlas of South India showing the Kyasanur forest disease reported districts (in orange). 
contaminated due to various reasons. The recent legislations on food safety, water quality, and Air pollution regulations are all indicators of the magnitude of this problem. Circumstances to consume food outside the safe walls of their own homes are increasing the chances of food-borne infections. Unmonitored social functions, hostels and employee canteens, packed foods, financial constraints leading to reuse of stored food, inadequate knowledge about the sources and routes of food poisoning, etc., are some of the common factors leading to such food poisoning episodes. Almost all districts are reporting such events, and most of them were found to be occurring in connection with some kind of social functions or in hostels. The causative organism is not usually identified, and the presenting symptoms are commonly diarrhea and vomiting. Though the state has a good reputation of having clean habits among its people, surveillance data is showing a trend on the other way [41]. A cluster of Guillain-Barre (GB) Syndrome was reported from one of the districts in Kerala, and the exact cause is yet to be identified, Infection with Campylobacter sp. is a well-known cause of GB syndrome [42], which are common food/milk-borne pathogen. Food safety standards in most places are not abided, food materials are produced and marketed raw, there are usually no safety labels on many of the items, the storage and handling is by default rather than by a qualified person, above all, there are no regular monitoring mechanism for these items. The service providers in emergency departments of most hospitals need sensitization on proactive steps to be taken for identifying the causative agent of FP episodes. Teaching hospitals or reference laboratories could go that extra mile in isolating the specific microbe in FP outbreaks. Kerala state having the highest density of population, and fast growing economic activities all round, is likely to witness more of such episodes in future, and hence there should be an immediate mechanism for addressing the issue. The scope for One Health intervention is too obvious here. Suggested plan of intervention could be:

- Set up a Foodborne infection research and Analytical unit under the center, with state of art Microbiology and chemical analysis division.

- Surveillance and research on Salmonella, Cambylobacter, and Escherichia coli on a priority basis.

- Collaborate with Food Safety Department, Health Department, Veterinary Department, and Agriculture and Forensic departments for joint action.

- Identify a mechanism for instant data sharing of the FP outbreaks, and arrange for a joint investigation.

- Sensitize the primary, secondary, and tertiary care functionaries on FP and also on timely sample collection, storage and transportation to specially designated laboratories.
- Organize training cum demonstration sessions on Standard food handling practices to the community, caterers, and food handlers.

- Formulate policy guidelines for enforcing safety levels of preservatives, adjuvants, growth promoters, etc., for food items including chicken, meat and dairy items.

- Advocacy for food safety, water safety measures and hand hygiene.

\section{Influenza Like Illnesses}

Influenza is the specific terminology for viral infections caused by the influenza A and B group of viruses in human beings. The symptoms consisting of mild fever, myalgia, rhinitis, and mild cough are by far the most common infectious diseases in any country. But periodic mutation of the virus of type A has caused global epidemics since the last century [43]. These epidemics had varying the degree of morbidity and mortality. In the recent years, researchers have identified the genomic segments undergoing mutations and also the reservoirs of such processes. Consequently, variants designated as H5N1 (Bird flu) and H1N1 (Swine flu) have spread in many countries $[44,45]$. Deaths have occurred among humans as wells the primary hosts of these infections and the genetic phenomenon of antigenic variation is expected to emerge during the years to come resulting in much more lethal impact on human and animal health. The SARS outbreak of East Asian countries during 2003-04 [46], the MERS Co.V [47] outbreak of Middle East countries in 2014 are also similarly evolved viral diseases having a great public health impact.

In this context, strict surveillance is needed in poultry and pig farms in Kerala state also. Because of the states' special geoclimatic conditions, where in large number of migratory birds flock in many districts [48], also having pig and poultry farms of varying sizes, researchers caution the conducive environment for viral mutation and amplification leading to emergence of newer variants of influenza virus with pandemic potential. Pigs also are amplifiers of Japanese encephalitis viruses. The experience of swine markets of Mexico triggering the H1N1 pandemic [49] and live bird markets of China [50] initiating the SARS and more recently the H7N9 outbreaks should be sufficient warning for the public health professionals all over the world.

\section{Conclusion}

Kerala State in South India is globally recognized as having unique developmental indicators in both social and health sectors. Good health indicators were achieved much ahead of other states in the country. But currently the state is passing through a phase of epidemiological transition, with common vaccine-preventable diseases under control, while other epidemic-prone communicable diseases and non-communicable diseases posing greater challenges in its public health arena. Diseases like Leptospirosis have established 
endemicity in most districts, Human Rabies is claiming 10-12 lives every year, Japanese encephalitis is spreading to more foci, Human influenza has spread all over the state, Avian influenza has shown its presence in the recent months, and many more zoonotic infections have shown early warning signals of their presence in the community. All these situations necessitate comprehensive investigations by multidisciplinary teams, from both human health side and animal health departments. Prevention and control strategies cut across both the human as well as animal reservoirs. Sharing of infrastructure facilities like specialized laboratories of diagnosis of such diseases can be mutually complementary for the well-being of all living being in this globe.

The authors who were directly involved in the disease surveillance program of the state for the past many years, emphatically opines that the One Health concept is most suitable for addressing the emerging public health challenges of the state. The field investigation of Lyme disease in one of the districts of the state has been shown as a successful model of One Health approach implemented in the ground level (Table-4).

Table-4: A synopsis for One Health intervention into the priority areas.

\begin{tabular}{|c|c|c|}
\hline $\begin{array}{l}\text { S. } \\
\text { no. }\end{array}$ & $\begin{array}{l}\text { Priority } \\
\text { disease }\end{array}$ & Intervention strategy \\
\hline 1 & Leptospirosis & $\begin{array}{l}\text { Joint outbreak investigations } \\
\text { Set up MAT* center at KVASU** } \\
\text { Serovar identification of circulating } \\
\text { Leptospirae } \\
\text { Education of farmers on minimizing } \\
\text { exposures }\end{array}$ \\
\hline 2 & $\begin{array}{l}\text { Japanese } \\
\text { Encephalitis }\end{array}$ & $\begin{array}{l}\text { Serosurveillance of Animal reservoirs } \\
\text { Identification of Hotspots in Kerala }\end{array}$ \\
\hline 3 & Rabies & $\begin{array}{l}\text { Collaborative efforts for Rabies Free } \\
\text { Kerala by } 2025 \\
\text { Special campaigns with } \\
\text { stakeholders (e.g. World Rabies Day) }\end{array}$ \\
\hline 4 & Brucellosis & $\begin{array}{l}\text { Set up surveillance system } \\
\text { Formulate policy guidelines for } \\
\text { personal protection of farmers }\end{array}$ \\
\hline 5 & Anthrax & $\begin{array}{l}\text { Advocacy for vaccination program } \\
\text { Education of high-risk groups on } \\
\text { personal protection }\end{array}$ \\
\hline 6 & $\begin{array}{l}\text { Lyme } \\
\text { disease }\end{array}$ & $\begin{array}{l}\text { Collaboration for outbreak investigation } \\
\text { and laboratory confirmation }\end{array}$ \\
\hline 7 & KFD & $\begin{array}{l}\text { Set up Animal surveillance system } \\
\text { Long-term research on evolving } \\
\text { epidemiology of KFD }\end{array}$ \\
\hline 8 & $\begin{array}{l}\text { Foodborne } \\
\text { infections }\end{array}$ & $\begin{array}{l}\text { Collaboration in outbreak investigation } \\
\text { Laboratory support for pathogen } \\
\text { identification } \\
\text { Research and surveillance of } \\
\text { Campylobacter and Escherichia coli } \\
\text { Training and demonstration programs } \\
\text { on food safety measures }\end{array}$ \\
\hline 9 & Influenza & $\begin{array}{l}\text { Surveillance on poultry and pig farms } \\
\text { for ILI }\end{array}$ \\
\hline 10 & Cholera & Surveillance of natural sources of vibri \\
\hline
\end{tabular}

*MAT: Microscopic Agglutination test, ${ }^{*}$ KVASU: Kerala Veterinary and Animal Sciences University, KFD: Kyasanur forest disease

\section{Authors' Contributions}

ASP designed the concept of review. AS drafted and revised the manuscript under the guidance of ASP. Both authors read and approved the final manuscript.

\section{Acknowledgments}

Sincere thanks to State Surveillance Officer IDSP, Kerala, and all support staff of the Integrated disease surveillance units in various districts for allowing to use the data in their database, which is the backbone of this paper. Dr. V. K. Vinod kumar, Assistant Professor, Veterinary College, Pookode is profusely thanked for permission given to use his research data on Anthrax and am deeply indebted to Dr. Prejit Nambiar, Officer in charge of Center for One Health Education, Advocacy, Research and Training (COHEART) at Kerala Veterinary and Animal Sciences University, Pookode, Wayanad district, Kerala, for being the driving force. Sincerely thanks to Mr.P.Rafi, District epidemiologist, Wayanad District, Kerala, for permitting us to use the Google map created in connection with the Kyasanur Forest Disease".

\section{Competing Interests} interests.

The authors declare that they have no competing

\section{References}

1. Available from: http://www.agricoop.nic.in. Kerala agricultural contingency plan for districts and www.mapsofindia.com/geocordinates of Kerala state. [Last accessed on 2014 Oct 10).

2. Census India 2011. Available from: http://www.censusindia.co.in/states [Last accessed on 2014 Oct 05].

3. McKibben B. What is true development? The Kerala Model. Available from: http://www.ashanet.org/libary/article.199803/html. [Last accessed on 2014 Oct 09].

4. Panicker PG. Health Transition in Kerala. Available from: http://www.cds.ac.in/krpcds/publications/panicker/html. [Last accessed on 2014 Oct 10].

5. Migrant workers population in Kerala touch 2.5M: The Hindu-Businessline article, published on 16 Feb 2013. Available from: http://www.thehindubusinessline.com/ Thiruvanthapuram. [Last accessed on 2013 Feb 16].

6. Suchithra M. Stench in my backyard; down to earth. In: Pellow DN, editor. Garbage Wars; Struggle for Environmental Justice in Chicago. Cambridge, MA: MIT Press; 2012.

7. Walsh JF, Molyneux DH, Birley MH. Deforestation: Effects on vector-borne disease. Parasitology 1993;106 Suppl: S55-75.

8. Pray L, Lemon S. Workshop summary, forum of microbial threat. Impact of Globalization on Infectious Disease Emergence. Ch. 2. Washington, DC.: National Academies Press; 2006.

9. Sugathan TN, Soman CR, Sankaranarayanan K. Behavioural risk factors for non-communicable diseases among adults in Kerala, India. Indian J Med Res 2008;127(6):555-63.

10. Integrated Disease Surveillance Program, State Surveillance Unit Data Base, DHS Kerala.

11. Guidelines for Prevention and Control of Leptospirosis. WHO-GOI 2006. p. 3. Published by National Institute of Communicble diseases, New Delhi.

12. Kuriakose M, Eapen CK, Paul R. Leptospirosis in 
Kolenchery, Kerala, India: epidemiology, prevalent local serogroups and serovars and a new serovar. Eur J Epidemiol 1997;13(6):691-7.

13. Available from: http://www.dhs.kerala.gov.in/public health/ idsp. [Last accessed on 2014 Oct 04].

14. Available from: http://www.prokerala/climate/html. [Last retrieved on 2013 May 16].

15. Sivakumar S. Leptospirois, current scenario in India. Med Update 2008;18:799-809.

16. Vijayachari P. Handbook on Leptospirois. Port Blair: Regional Medical Research Center; 2010.

17. Personal Communication from Dr. Mariyamma Kuriakose, MM Hospital, Kolenchery, Kerala. India.

18. Ambily R, Mini M, Joseph S, Krishna SV, Abhinay G. Canine leptospirosis - A seroprevalence study from Kerala, India. Vet World 2013;6(1):42-4.

19. Sugunan AP. Epidemiology of leptospirosis. Laboratory Manual on Leptospirosis. Port Blair: Regional Medical Research Centre; 2007.

20. Japanese Encephalitis. Available from: http://www.icmr. nic.in/pinstitute/niv/pdf. [Last accessed on 2014 Aug 20].

21. Changbunjong T, Weluwanarak T, Taowan N, Suksai P, Chamsai T, Sedwisai P. Seasonal abundance and potential of Japanese encephalitis virus infection in mosquitoes at the nesting colony of ardeid birds, Thailand. Asian Pac J Trop Biomed 2013;3(3):207-10.

22. van-den-Hurk AF, Ritchie SA, Johansen CA, Mackenzie JS, Smith GA. Domestic pigs and Japanese encephalitis virus infection, Australia. Emerg Infect Dis 2008;14(11):1736-8.

23. Garmendia AE, Van Kruiningen HJ, French RA. The West Nile virus: Its recent emergence in North America. Microbes Infect 2001;3(3):223-9.

24. Rabies. Fact sheet, 2013. Available from: http://www.who. int/. [Last accessed on 2014 Sept 20].

25. Government of Kerala Order No. GO (MS) no.557/2008/ H\&FWD. Thiruvananthapuram Dated 31 October 2008. Guidelines RegImplementation of Intra Dermal Rabies Vaccination (IDRV) in Kerala.

26. Available from: http://www.cdc.gov/brucellosis. [Last accessed on 2014 Sep 30].

27. Al-Nasser W. In: Bronz MS, editor. e medicine article on brucellosis. Available from: http://www.e-medicine.medscape.com/article/213430.

28. Sidell FR, Takafuji ET, Franz DR. Medical Aspects of Chemical and Biological Warfare. Washington, DC: US Department of Health and Human Services: Office of the Surgeon General; 1997. p. 514-21.

29. Outbreak Report from District Surveillance Unit, Malappuram, Kerala, week. 12/2014 dated 22.3.14.to State Surveillance unit of IDSP.

30. Reddy RR, Prejit N, Sunil B, Vinod VK, Asha K. Seroprevalaence of brucellosis in slaughter cattles of Kerala, India. J Foodborne Zoonotic Dis 2014;2:27-9.

31. Fact Sheet on Anthrax: Available from: http://www.cdc.gov.
[Last accessed on 2014 Sep 20].

32. Bio terrorism and anthrax spores. Available from: http://www.defencejournal.com/dec98/anthrax.html. [Last accessed on 2014 Sep 20].

33. Rahman H, Gajendragad MR, Uma S. NADRES Report. ICAR, Hebbal, Bangaluru, India 2012. [Last accessed on 2014 Sep 20].

34. http://www.who.int/en. Lyme disease, Lyme disease. Available from: http://www.cdc.gov. [Last accessed on 2013 Feb 26].

35. Early Warning Signal Report from IDSP DSU Wayanad, 25-2-2013.EWS report sent to State Surveillance Unit of IDSP from District Surveillance Unit, Wayanad, Kerala, dated 25-2-2013.

36. Telford H. Work, Harold Triapide-Viral Research Center Pune, 1957: Kyasanur Forest Disease, Proceedings of $9^{\text {th }}$ Pacific Science Congress; 1957.

37. FIRs from DSU Wayanad in Dec 2012 and May 2013 and DSU Malappuram May 2014.

38. Report as per ref. no NIV.135724/MCL.13-H-127.

39. Communication from NIV Pune to ADPH and SSO Kerala, reg KFD outbreak in Malappuram dated 4-6-14.

40. Report on Monkey death-O/o Dy director, Viral Diagnsotic lab Shimoga: VDL/PR-1/Wkly/213/13-14. dated 1-3-14.

41. Consolidated data on food poisoning. IDSP Kerala State Surveillance unit. Trivandrum. 2013-2014.

42. MMWR. Feb 27/1998;47(07):129-31. GB Syndrome and Cambylobacter infection- and Global review of Cambylobacterioses (WHO) Report of Expert Consultation. Utrecht, Netherlands, 2012. p. 9.

43. Pandemic Influenza updates from Global Alert and Response Network-WHO.www.who.int/en/GAR/Pandemic Influenza H1N1.2009. [Last accessed on 2014 Oct 10].

44. H5N1 outbreak China www.who.int/en/GAR/DON archives/avian influenza H5N1 China update, 2006. [Last accessed on 2014 Nov 15].

45. H1N1 outbreaks - Mexico 2009 and USA 2009.www. who.int/en/GAR/archives/Swine flu in USA and Mexicoupdate2.April 2009. [Last accessed on 2014 Nov 15].

46. SARS outbreak-China 2003.www.who.int/en/GAR/ archives/multicountry outbreak of SARS/update 1-65/April 2003. [Last accessed on 2014 Nov 15].

47. MERS Corona Virus outbreak-April 2014.www.who.int/en/ GAR/Middle East Corona Virus outbreak in Saudi Arabia, March 2014, [Last accessed on 2014 Jun 20].

48. Migratory bird sanctuaries in Kerala.www.forest.kerala. gov.in/migratory birds/ [Last accessed on 2014 Nov 20].

49. Global Alert and Response Network: Influenza outbreak updates: 24 April, 2009.www.who.int/en/GAR/archives/ Influenza outbreak updates. [Last accessed on 2014 Nov 15].

50. Mission Report: Joint China WHO Mission on H7N9 Influenza Infection: 18-24 April, 2013.www.who.int/en/ GAR/Influenza outbreak/H7N9 update 2013. [Last accessed on 2014 Nov 15].. 